\title{
Therapeutic efficacy of Trifolium pratense $L$. on letrozole induced polycystic ovary syndrome in rats
}

\author{
Abbasian $\mathrm{Z}^{1}$, Jafari Barmak $\mathrm{M}^{2}$, Barazesh $\mathrm{F}^{1}$, Ghavamizadeh $\mathrm{M}^{1}$ \& Mirzaei $\mathrm{A}^{3^{*}}$ \\ ${ }^{1}$ Student Research Committee, Yasuj University Medical Sciences, Yasuj, Iran \\ ${ }^{2}$ Cellular \& Molecular Research Center, Yasuj University of Medical Sciences, Yasuj, Iran \\ ${ }^{3}$ Medicinal Plants Research Center, Yasuj University of Medical Sciences, Yasuj, Iran \\ *Email: ali.mirzaei@yums.ac.ir
}

\section{ARTICLE HISTORY}

Received: 18 June 2020

Accepted: 10 August 2020

Published: 01 September 2020

\section{KEYWORDS}

Red clover

Endocrine disorders

Clomiphene

Antioxidant

Inflammation

\section{ABSTRACT}

Polycystic ovary syndrome (PCOS) is considered as one of the leading endocrine disorders during reproductive age in women. This study designed to determine the therapeutic effects of red clover (Trifolium pratense) on letrozole-induced PCOS in vivo. Forty female Sprague-Dawley rats were equally divided into five groups. Control group with a regular sexual cycle received normal saline (letrozole vehicle). Letrozole (1 $\mathrm{mg} / \mathrm{kg}$ ) was used to induce the PCOS to the rats in the treatment groups. After induction of PCOS, four treatment groups received the normal saline, or clomiphene citrate $(1 \mathrm{mg} / \mathrm{kg})$, or red clover extracts $(500$ or $750 \mathrm{mg} / \mathrm{kg}$ ) for 30-days. After treatment, ovary and uterus were removed, weighed, and the ovaries were subjected to histopathological studies. Serum testosterone and estradiol levels, antioxidant activities, and lipid profiles were evaluated. Red clover extracts and clomiphene citrate decreased testosterone levels and showed a significant increase in estradiol levels in comparison to PCOS induced group $(p<0.05)$. Red clover administration restored the GSH, SOD and CAT levels $(p<0.05)$ and decreased the NO and MDA levels $(p<0.05)$. Treatments caused no significant change in levels of TG, TC, and FBG factors when compared to PCOS induced group ( $P>0.05)$. However, red clover $(750 \mathrm{mg} / \mathrm{kg})$ significantly increased $\mathrm{HDL}$ and decreased LDL levels when compared to PCOS induced group $(P<0.05)$. Treatment with red clover reduced ovarian weight, volumes of ovarian, medulla, cortex and number of cysts and increased number of oocytes compared to PCOS group. Both red clover and clomiphene citrate could treat the letrozole induced PCOS in rats; however, red clover indicated antioxidant activities more than clomiphene citrate. Red clover may be used for discovering anti-PCOS drugs with lower side effects.

\section{Introduction}

Polycystic ovary syndrome (PCOS) is one of the most common endocrine disorders in females. PCOS affects an estimated 4 to $15 \%$ of women in their reproductive age $(1,2)$; however, the aetiology and pathogenesis of this syndrome remain poorly understood. The features of this syndrome are infertility, alopecia, irregular menstrual cycles, acne and hirsutism $(3,4)$, and also metabolic disorders (insulin resistance, obesity and dyslipidemia), type 2 diabetes, cancer, coronary heart diseases, and hypertension $(5,6)$.

Changing the habits of life, surgery, and medication are widely followed therapies for PCOS. The most recognized medications are clomiphene citrate therapy, metformin, and tamoxifen $(7,8)$. There are a variety of side effects such as arthritis, muscle pain and psychological disturbance in drugs that have been used for management of PCOS $(9,10)$. Due to side effects caused by chemical drugs, the medicinal plants are gaining interest in the prevention and treatment of diseases (11-13). Therefore, the present focus is being laid on natural medicinal plants with minimum side effects.

Red clover with scientific name Trifolium pratense L. is one of 250 different species of the Trifolium genus, which belongs to the Leguminosae or Fabaceae plant family (14).Red clover has a wide variety of biological potential in traditional medicine such as anti-cancer, antioxidant, estrogenic and

(c) Abbasian et al (2020). This is an open-access article distributed under the terms of the Creative Commons Attribution License, which permits unrestricted use, distribution, and reproduction in any medium, provided the original author and source are credited (https://creativecommons.org/licenses/by/4.0/).

To cite this article: Abbasian Z, Jafari B M, Barazesh F, Ghavamizadeh M, Mirzaei. A Therapeutic efficacy of Trifolium pratense L. on letrozole induced polycystic ovary syndrome in rats Plant Science Today. 2020;7(3):501-507. https://doi.org/10.14719/pst.2020.7.3.845 
progestogenic activities $(15,16)$. The aerial part of this plant has four isoflavones including biochanin A, formononetin, genistein, and daidzein (17). These phytochemicals have shown a lot of interest due to their human health benefits. Red clover isoflavones are estrogen receptor beta, strong agonists. They have selective estrogen receptor modulator potential and consequence, display a positive effect on menopausal symptoms (18). In addition, isoflavones belong to phytoestrogen class are useful for the treatment of cardiovascular disease, osteoporosis, menopausal symptoms, and even cancer (19). Regarding to the effects of the red clover and its compounds on human health, the aim of this study was to evaluate the therapeutic efficacy of red clover on letrozole-induced polycystic ovary syndrome.

\section{Materials and Methods}

\section{Herbal extract preparation}

Red clover (Trifolium pratense L.) was collected from Yasuj (Iran) in June 2016. The plant identified in the Herbal Medicinal Research Center of Yasuj University of Medical Sciences (Voucher no. HMRC-r 15). Plant materials were extracted with $70 \%(\mathrm{v} / \mathrm{v})$ ethanol by maceration method at room temperature for $24 \mathrm{~h}$.

\section{Grouping and treatments}

In this study, adult female Sprague-Dawley rats were acquired from Shiraz Animal House and were kept in the room at controlled conditions of temperature $25 \pm$ $2{ }^{\circ} \mathrm{C}, 56 \pm 5$ humidity and 12-h daily cycle for 7 days to be acclimatized. They were fed with the conventional pellet food (Behparvar Com., Iran) and water ad libitium during of study. All procedures of the study were performed according to the approved local Animals Ethics Committee (Protocol approval number: 150/2014).

Forty female Sprague-Dawley rats with regular estrus cyclicity were equally divided into 5 groups of 8 rats each. During the experiment, the rat's estrus cycle was determined on each group by vaginal smear using Giemsa stain to confirm the induction of PCOS. If the rats exhibited acyclic/irregular ovarian cyclicity, they were considered as PCOS positive. Induction of polycystic ovary syndrome was performed using letrozole (Femara, Novartis, Istanbul, Turkey) administered to the rats $(1 \mathrm{mg} / \mathrm{kg}$ dissolved in $0.9 \% \mathrm{NaCl}$ solution) p.o. once daily for 21 consecutive days (20).

Animal models of PCOS has offered a useful method for pathophysiology study of the syndrome. Presently, these models including administration of Estradiol Valerate, DHEA, prepubertal androgen excess and letrozole have been developed. These models mimic mainly features of PCOS in women (21).

Letrozole is a potent non-steroidal aromatase inhibitor. It used as a PCOS model in some animal experiment with many histologic and biochemical finding similarity with human PCOS. In the most of the experimental research for inducing of PCOS using $400 \mu \mathrm{g} /$ day letrozole for 7-35 days (22).
Control or normal group with a regular sexual cycle that received normal saline (letrozole vehicle) orally for 21 days. All the experimental animals except control group were received letrozole. After 21 days, rats were divided into 4 groups as follows:

PCOS: rats were given 21 days letrozole and afterward 30-day normal saline. Standard: Animals received letrozole for 21 days and afterward administered with clomiphene citrate at a dose of 1 $\mathrm{mg} / \mathrm{kg}$ in $0.9 \% \mathrm{NaCl}$ solution per oral. Red clover (RC)500: was given 21 days letrozole and afterward treated with $500 \mathrm{mg} / \mathrm{kg}$ red clover extract orally for 30 days. RC-750: was given 21 days letrozole and afterward treated with $750 \mathrm{mg} / \mathrm{kg}$ red clover extract orally for 30 days.

\section{Blood sampling and biochemical assessments}

The animals were evaluated according to a relative number of leukocytes, epithelial and cornified cells, 24 hours after the last sex cycle. The animals were anesthetized with diethyl ether the last dose of the treatment after $24 \mathrm{~h}$ fasting and 3-5 ml of blood was collected by cardiac puncture. Finally, animals sacrificed and the ovary and uterus were removed, weighed and the ovaries were fixed 10\% buffered formalin and processed for histopathological study.

Serum was separated immediately and kept in a freezer at $-20^{\circ} \mathrm{C}$ for an estimate of biochemical parameters. Serum testosterone and estradiol were measured with commercially available ELISA kits. The assays were performed according to the manufacturer's instructions.

The activity of superoxide dismutase (SOD) was determined by spectrophotometer. The SOD activity was expressed in unit's/mg protein (23). Catalase (CAT) activity was estimated according to the method Beers and Sizer by spectrophotometer. One unit of the enzyme was defined as $m$ moles of $\mathrm{H} 2 \mathrm{O} 2$ $\mathrm{degraded} / \mathrm{min} / \mathrm{mg}$ of protein (24).

Glutathione (GSH) content was determined according to Jollow et al. (1974) method. The contents were expressed in micromoles/mg protein (25). MDA levels were estimated via thiobarbituric acid reacting substance (TBARS). The MDA levels were expressed in micromoles/mg protein (26).

Nitrate/nitrite was assayed according to the method of Green et al. (1982) method using Griess. The results were expressed as micromoles/mg protein (27).

Lipid profile [triglycerides (TG), total-cholesterol (TC), LDL-cholesterol (LDL-C) and HDL-cholesterol (HDL-C)] and FBG were measured according to commercial Iranian diagnostics kits in autoanalyzer.

\section{Stereological study}

\section{The volume of the ovary}

To estimate the volume of the ovary, the ovary was sectioned into isotropic uniform random (IUR) sections using the isotropic Cavalieri method and using a stereomicro-scope connected to a computer, at the final magnification of 20X. A brief description is presented under Figure 8 (28). The volume was determined via the following formula: 
Ovary volume $=\Sigma \mathrm{ni}=\mathrm{p} \times \mathrm{T} \times \mathrm{a}(\mathrm{p})$.

Where $\Sigma$ ni $=p$ considers as the total number of points superimposed on the images; $T$ considers as the distance between the sampled sections, and $a(p)$ considers as the area associated with each point.

\section{The volume of cortex, medulla, ovarian cysts}

The point counting technique was used to compute the volume of the structures via the following rule:

Volume of the structures $=\Sigma \mathrm{P}($ structure $) / \Sigma \mathrm{P}$ (total)

Where $\Sigma \mathrm{P}$ (structure) and $\Sigma \mathrm{P}$ (total) consider as the total points striking the aim structure and the total points striking the ovary sections, respectively.

\section{Estimation of the number of oocytes}

The number of atretic oocytes, antral and preantral was determined using a light microscope. The ovary specimens from all experimental groups were sectioned into $5 \mu \mathrm{m}$ thicknesses, stained with hematoxylin-eosin (HE) and pathologicalphysiological structures were studied on a PC in conjunction with a (Nikon E200 microscope, Tokyo, Japan) with a $60 \times$ oil immersion objective.

\section{Statistical methods}

The collected data were statistically analyzed by oneway ANOVA followed by post hoc analysis. Tests were carried out in triplicate. The data were expressed as the Mean \pm S.D. The $P$ value less than 0.05 considered as significant.

\section{Results and Discussion}

In the present study was aimed to evaluate the therapeutic efficacy of red clover (Trifolium pratense) on letrozole-induced PCOS in rats, both red clover and clomiphene citrate could treat the letrozole induced PCOS in rats; however, red clover indicated

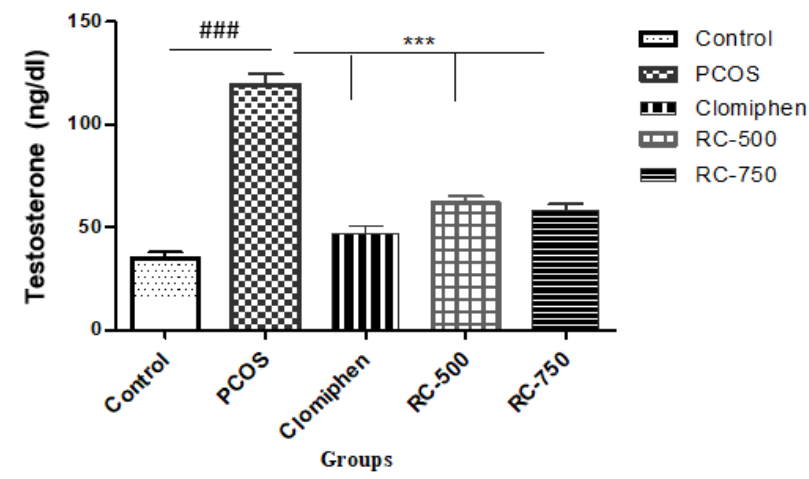

Fig. 1. Effect of red clover extract on serum concentrations of testosterone in letrozole-induced PCOS rats.

Control: Normal saline recipient; PCOS: Letrozole recipient; RC-500: Red clover $500 \mathrm{mg} / \mathrm{kg}$ recipient; RC-750: Red clover $750 \mathrm{mg} / \mathrm{kg}$ recipient. Statistical analysis was carried out by one-way ANOVA followed by Tukey's multiple.\# denotes statistical significance in comparison to normal group rats *denotes statistical significance in comparison to PCOS group rats \#\#\# $\mathrm{p}<0.001$; *** $\mathrm{P}<0.001$.

higher antioxidant activities than clomiphene citrate.

The serum level of testosterone was significantly increased in PCOS-induced rats group by letrozole $(p<0.001)$ at the terminal day of the study in comparison to control group. Red clover and clomiphene citrate $(\mathrm{p}<0.001)$ successfully restored

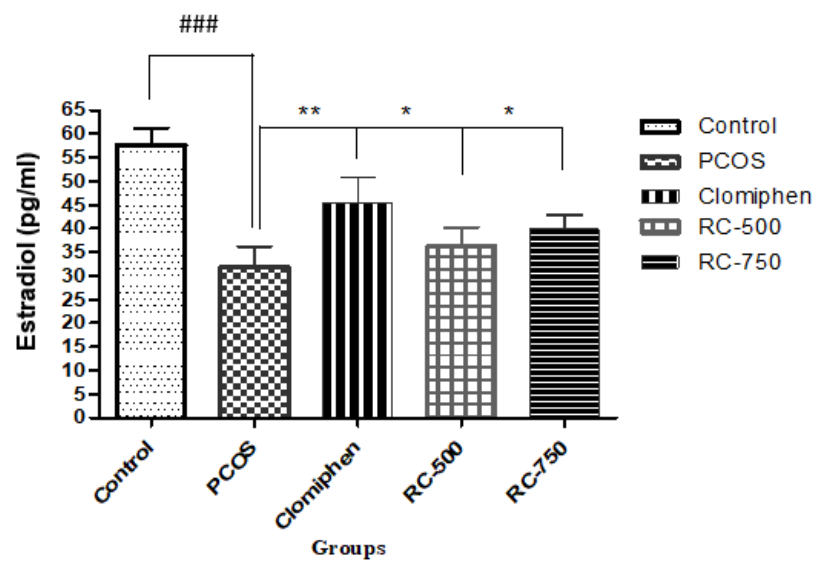

Fig. 2. Effect of red clover treatment on serum concentrations of estradiol in letrozole-induced PCOS rats.

Control: Normal saline recipient; PCOS: Letrozole recipient; RC 500: Red clover $500 \mathrm{mg} / \mathrm{kg}$ recipient; RC-750: Red clover $750 \mathrm{mg} / \mathrm{kg}$ recipient. Statistical analysis was carried out by one-way ANOVA followed by Tukey's multiple.

\# denotes statistical significance in comparison to normal roup rats *denotes statistical significance in comparison to PCOS group rats \#\#\#p<0.001; ${ }^{*} \mathrm{P}<0.05,{ }^{* *} \mathrm{P}<0.01,{ }^{* * *} \mathrm{P}<0.001$

testosterone levels in comparison to PCOS induced group (Fig. 1).

Induction of PCOS indicated a significant

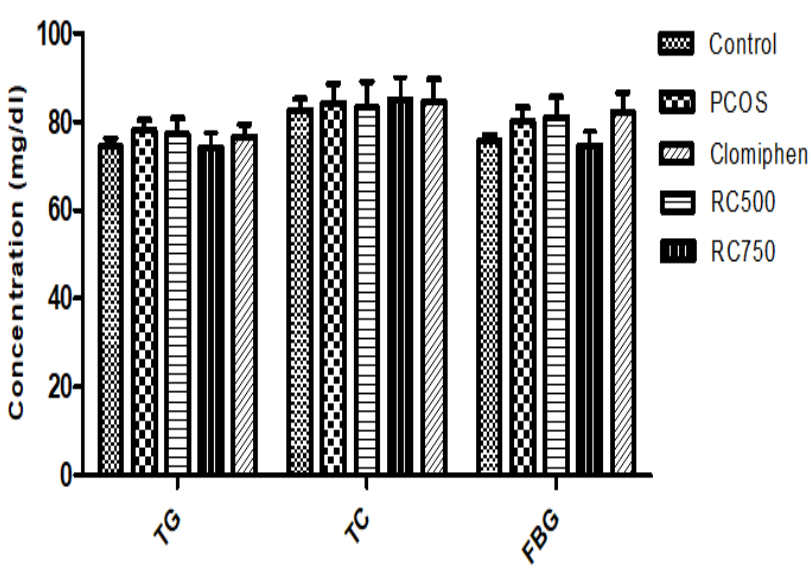

Fig. 3. Effect of red clover treatment on serum concentrations of TG,

TC and FBG in letrozole-induced PCOS rats. Control: Normal saline recipient; PCOS: Letrozole recipient; RC-500: Red clover $500 \mathrm{mg} / \mathrm{kg}$ recipient; RC-750: Red clover $750 \mathrm{mg} / \mathrm{kg}$ recipient. Statistical analysis was carried out by one-way ANOVA followed by Tukey's multiple.

decrease $(p<0.001)$ in estradiol level at the last day of the study. Oral administration of red clover and clomiphene citrate showed a significant increase in estradiol levels in comparison to PCOS rats (Fig. 2).

In PCOS induced group, levels of TG, TC, and FBG increased; but it was no significantly $(\mathrm{P}>0.05)$ in comparison to control rats (Fig. 3). However, LDL and HDL levels were markedly restore $(\mathrm{P}<0.05)$ in comparison to PCOS induced group (Fig. 4). 


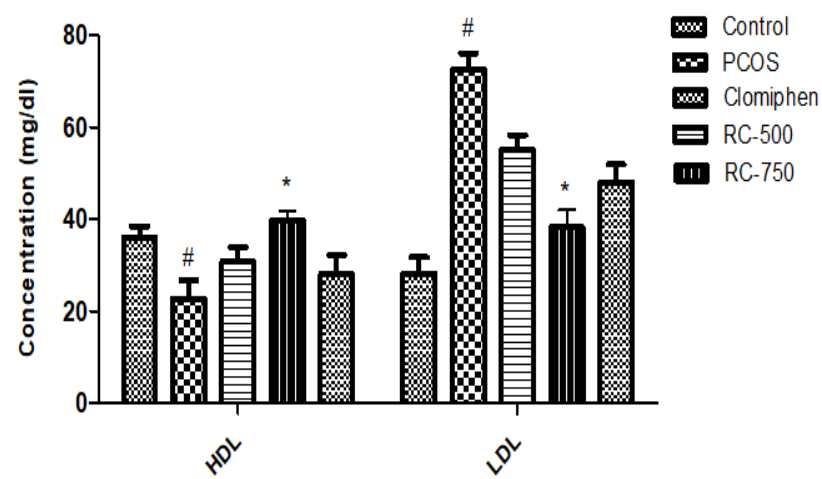

Fig. 4. Effect of red clover treatment on serum concentrations of HDL and LDL in letrozole-induced PCOS rats.

Control: Normal saline recipient; PCOS: Letrozole recipient; RC500:Red clover $500 \mathrm{mg} / \mathrm{kg}$ recipient; RC-750: Red clover $750 \mathrm{mg} / \mathrm{kg}$ recipient. Statistical analysis was carried out by one-way ANOVA followed by Tukey's multiple.

\# denotes statistical significance in comparison to normal group rats.

*denotes statistical significance in comparison to PCOS group rats $\# \mathrm{p}<0.05 ;{ }^{*} \mathrm{P}<0.05$.

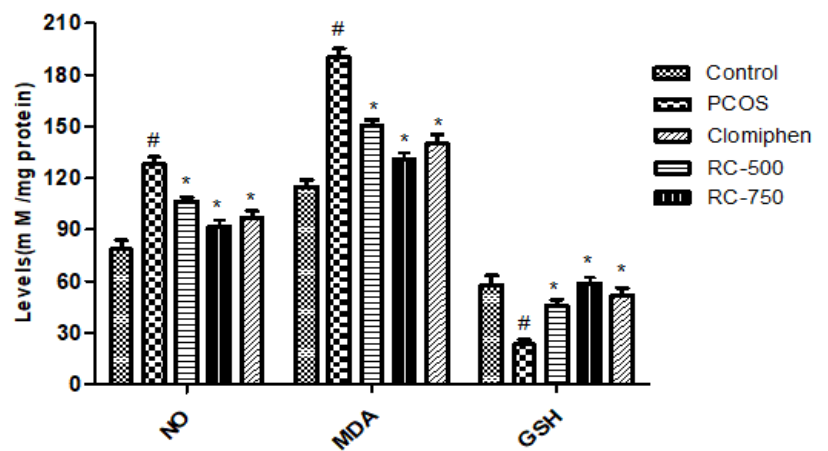

Fig. 5. Effect of red clover treatment on serum concentrations of NO, MDA and GSH in letrozole-induced PCOS rats.

Control; Normal saline recipient, PCOS; Letrozole recipient, RC500: Red clover 500 mg/kg; RC750: Red clover 750 mg/kg; Statistical analysis was carried out by one-way ANOVA followed by Tukey's multiple.

\# denotes statistical significance in comparison to normal group rats.

*denotes statistical significance in comparison to PCOS group rats.

In comparison to control rats, PCOS rats significantly indicated an elevation $(\mathrm{p}<0.05)$ in $\mathrm{NO}$ and MDA levels. Treatment with red clover significantly $(\mathrm{p}<0.05)$ decreased the MDA and NO levels in treatment rats (Fig. 5).

Administration of letrozole decreased $(p<0.05)$ the SOD, CAT activities, and GSH levels in PCOS rats in comparison to control rats. In comparison to vehicle-treated PCOS rats, red clover administration significantly increased $(\mathrm{p}<0.05)$ the SOD and CAT activities $(\mathrm{P}<0.05)$. Red clover successfully restores the GSH levels $(\mathrm{P}<0.05)$ (Fig. 6).

In order to develop polycystic ovary syndrome, letrozole, a non-steroidal aromatase inhibitor was used. In this case, androgens cannot convert to estrogens and resulted in the elevation of androgen and consequently fall in estrogen levels(29). Besides, the increased level of testosterone in plasma, that resulted in prolonged diestrus phase and it was followed by an increase in body weight of PCOS group rats $(30,31)$. Administration of long-term

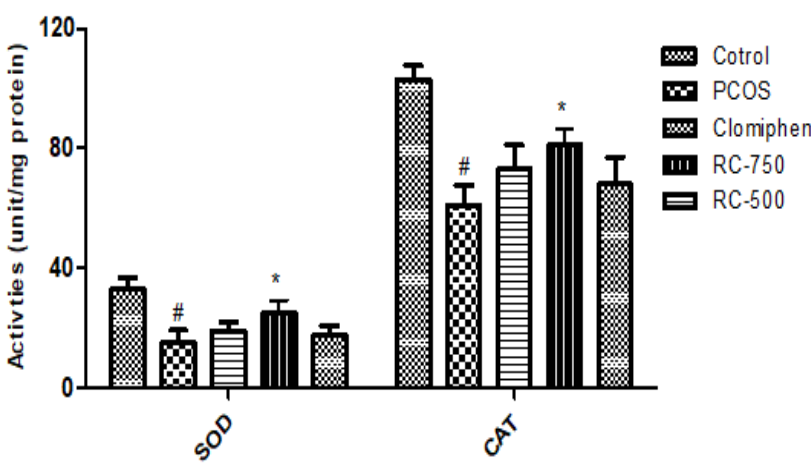

Fig. 6. Effect of red clover treatment on serum concentrations of SOD and CAT in letrozole-induced PCOS rats.

Control; Normal saline recipient, PCOS; Letrozole recipient, RC500: Red clover $500 \mathrm{mg} / \mathrm{kg}$; RC750: Red clover $750 \mathrm{mg} / \mathrm{kg}$; Statistical analysis was carried out by one-way ANOVA followed by Tukey's multiple.

\# denotes statistical significance in comparison to normal group rats.

*denotes statistical significance in comparison to PCOS group rats. $\# \mathrm{p}<0.05 ;{ }^{*} \mathrm{P}<0.05$.

herbal extracts with phytoestrogens compounds can reduce plasma testosterone levels by the negative feedback effect on LH hormone (32). Administration of red clover extract was able to normalize testosterone and estradiol concentration in comparison to PCOS rats group. According to earlier reports, red clover with antiandrogenic properties and high content of phytoestrogens such as isoflavones in the plant may reduce androgen levels. Red clover isoflavones are weak agonists of estrogen alpha receptors (ERa) and potent agonists of estrogen beta receptors (33). Moreover, the phytochemical compounds of red clover such as genistein and daidzein could interfere with steroid formation in rat adrenal and consequence decreased testosterone levels $(34,35)$. In addition, coumestrol, biochanin, phytoestrogens and zearalenol have inhibitory effects on steroidogenic enzyme activity of 17 betahydroxysteroid dehydrogenases (17 $\beta$-HSD) which result in reduced androgens synthesis (36).

In the present study, treatments caused no significant change in levels of TG, TC, and FBG factors as compared to PCOS induced group. However, red clover $(750 \mathrm{mg} / \mathrm{kg})$ significantly increased HDL and decreased LDL levels when compared to in PCOS induced group. Letrozole-induced PCOS rats did not indicate significant changes in FBG, TC, and TG levels. The reason for this type of result was that letrozole did not have any effects on insulin signaling pathways (5). In addition, the letrozole-induced rodent model of PCOS did not show any metabolic aberrations such as adiposity, insulin sensitivity, and dyslipidemia, which were reported in parallel with some studies (21).

Oxidative stress is considered as an important pathological feature of PCOS. It causes a change in oxidant-antioxidant profile. Hence, women with PCOS indicate a decreased level of total antioxidant status (37). In the current study, oxidative stress markers (MDA and NO) were increased in PCOS animals. However, endogenous antioxidants (SOD, CAT and GSH levels) in blood were decreased. 
Treatment with red clover significantly reduced markers of oxidative stress such as MDA and NO and increased the level of potential antioxidant markers such as, GSH, CAT, and SOD in letrozole-induced PCOS model of rats. SOD is an antioxidant enzyme in live organisms. It protects the tissues and cell against damages caused by superoxide radicals. SOD reduces superoxide radicals generated by cell injuries via conversion of superoxide radicals into hydrogen peroxide (38). Superoxide scavenging capacity of plant extract may be mostly due to the presence of secondary phytochemicals such as total phenol and flavonoids. CAT enzyme hydrolyzes $\mathrm{H} 2 \mathrm{O} 2$ into $\mathrm{H} 2 \mathrm{O}$ and $1 / 2$ O2. This enzyme has an important role in protecting DNA, proteins, and cellular lipids (39). NO is a very useful mediator in some physiological and biologic pathways in the human body. Its antioxidant and antitumor potentials were reported in the literature $(40,41)$. Deviation in GSH levels could be an early marker in the development of PCOS. GSH is an important antioxidant present in all the cells. The level of this non-enzymatic antioxidant parameter may be because of increased turnover, to prevent oxidative damage. It protects cells against free radicals, peroxides and other toxic compounds (42, 43). Furthermore, lipid peroxidation is mostly used as an indicator for oxidative tissue injury, which leads to cell necrosis and inflammation. Inflammation results in the production of reactive oxygen species. Therefore, the studies indicated that the incidence of

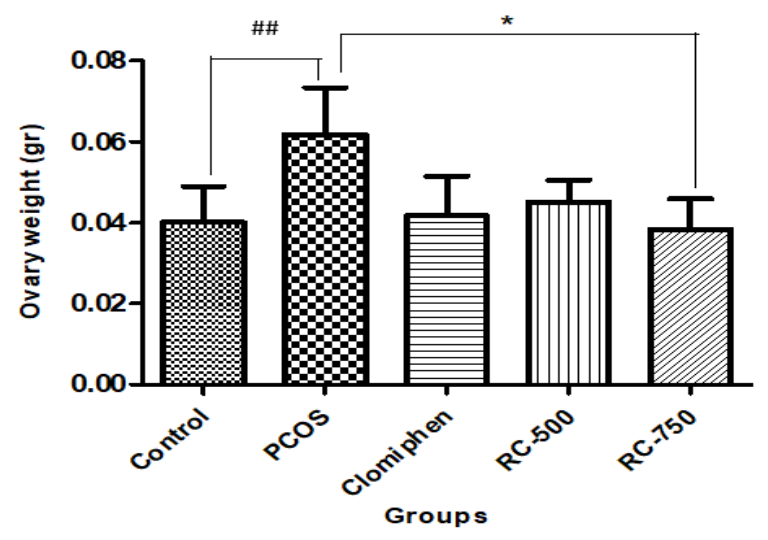

Fig. 7. Effect of red clover treatment on ovary weight in letrozole induced PCOS rats.

Control; Normal saline recipient, PCOS; Letrozole recipient, RC500: Red clover $500 \mathrm{mg} / \mathrm{kg}$; RC750: Red clover $750 \mathrm{mg} / \mathrm{kg}$; Statistical analysis was carried out by one-way ANOVA followed by Tukey's multiple.

\# denotes statistical significance in comparison to normal group rats.

*denotes statistical significance in comparison to PCOS group rats. $\# \# \mathrm{p}<0.01 ;{ }^{*} \mathrm{P}<0.05$.

PCOS was closely related to oxidative stress and chronic low grade inflammation $(44,45)$. In the present research, MDA is an indicator of lipid peroxidation that significantly increased in polycystic ovaries and red clover is able to restore it.

The ovarian weight in the PCOS group showed a significant increase compared to the normal group $(p<0.05)$ (Fig. 7). Consumption of clomiphene and red clover extracts significantly reduced $(p<0.05)$ ovarian weight compared to PCOS group (Fig. 7). Ovarian stereology study in PCOS group, the total volume of the ovary, cortex, medulla, and number of cysts were increased and a reduction is the number of oocytes compared with the control group. Treatment with red clover showed reduced volumes of ovarian, medulla

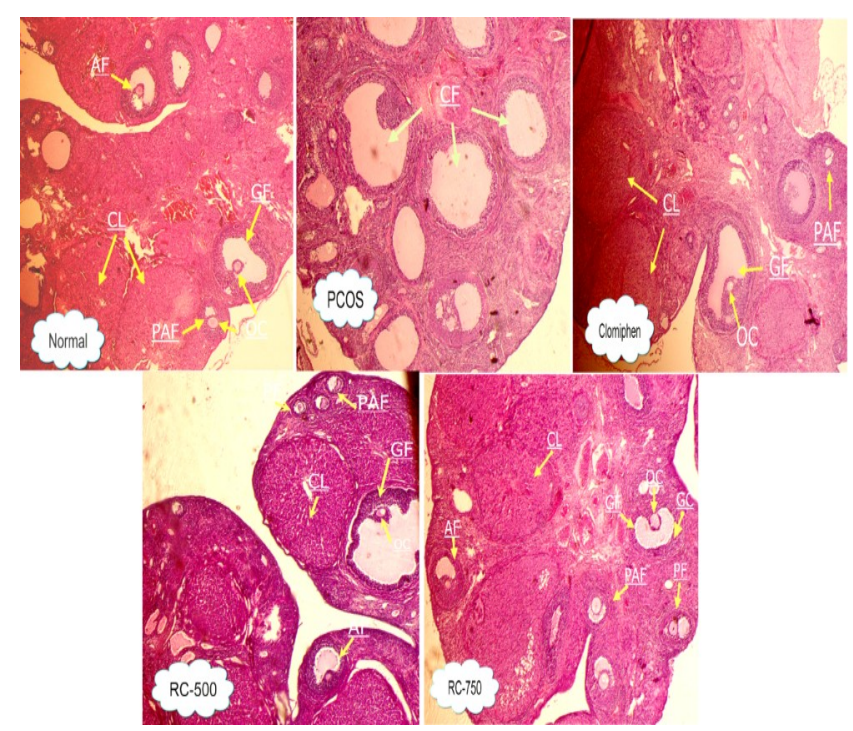

Fig. 8. Histological sections of rat ovary were stained with hematoxylin and eosin in different groups (20X magnification).

Control or Normal: saline recipient, PCOS; Letrozole recipient, RC500: Red clover $500 \mathrm{mg} / \mathrm{kg}$ recipient; RC-750: Red clover $750 \mathrm{mg} / \mathrm{kg}$ recipient; PF: Primary Follicle; PAF: Pre antral Follicle; AF: Antral Follicle; GF: Graf Follicle; CL: Corpus Luteum; OC: Oocyte. Letrozole-induced PCOS rats indicate large cystic follicles (CF); Red clover $500 \mathrm{mg} / \mathrm{kg}$ treated PCOS rats indicate well-defined thecal cell layer; Red clover $750 \mathrm{mg} / \mathrm{kg}$ treated PCOS rats indicate normal follicle.

and cortex. The number of cysts and number of oocytes are increased in respect of PCOS group.

The various histological studies revealed that a large number of cystic follicles were observed in PCOS group, however the cysts were not observed in other groups. Growth of ovarian follicles in the early stages did not occur. Their granulosa cells were destroyed and follicles became a cyst. Follicles were observed in the red clover treatment groups in different stages of growth (primary, preantral, antral and graphs) and corpus luteum that indicated ovulation (Fig. 8).

The volume of the cortex and total volume of the ovary were significantly reduced in the red clover groups as compared with the control rats. These results may be due to the absence of corpus luteum, reduction in the number of antral follicle, increase in the number of atretic follicles. Ovary atrophy occurs in the PCOS rats. Furthermore, red clover may induce oxidative stress and ovary apoptosis that can result in a reduction in the ovary volume.

Phytoestrogen has a chemical structural similarity or functional similarity to estrogens that resulted in similar hormonal activity, it further binds to estrogen receptors. Hence they have a protective effect against PCOS and hormone-dependent cancers. As isoflavones are major phenolic compounds found in addition to phytoestrogens in red clover, probably play important role of red clover in the prevention and treatment of PCOS (18). 


\section{Conclusion}

PCOS as a hormonal disorder common among women of reproductive age is one of the most common causes of female infertility. It has been reported that PCOS is a composite heterogeneous condition with multifactorial etiology like genetic, oxidative stress, and the environmental factors. The study indicated that red clover as a medicinal plant can be useful for treatment of PCOS similar to standard drug (clomiphene citrate). It is due to antioxidant properties of the plant that can be used as a potential source for production of natural antiPCOS drugs with lower side effects.

\section{Acknowledgements}

The authors are thankful to Yasuj University of Medical Sciences, Yasuj, Iran for providing necessary laboratory facilities.

\section{Authors' contributions}

AM and MJB designed the study. ZA, FB, and GZM contributed to carry out the experimental part of the work. All authors prepared the content of this manuscript and completed the final version.

\section{Conflict of interests}

The authors declare that there are no conflicts of interest.

\section{Ethical issues}

All procedures of the study were performed according to the approved local Animals Ethics Committee (Protocol approval number: 150/2014).

\section{References}

1. Azziz R, Woods KS, Reyna R, Key TJ, Knochenhauer ES, Yildiz BO. The prevalence and features of the polycystic ovary syndrome in an unselected population. J Clin Endocrinol Metabol. 2004;89(6):2745-9. https://doi.org/10.1210/jc.2003032046

2. Brutocao C, Zaiem F, Alsawas M, Morrow AS, Murad MH, Javed A. Psychiatric disorders in women with polycystic ovary syndrome: a systematic review and meta-analysis. Endocrine. 2018;62:318-25. https://doi.org/10.1007/s12020-018-1692-3

3. DuRant EM, Leslie NS, Critch EA. Managing polycystic ovary syndrome: a cognitive behavioral strategy. Nurs women's health. 2009;13(4):292-300. https://doi.org/10.1111/j.1751486X.2009.01439.x

4. Walters K, Bertoldo M, Handelsman D. Evidence from animal models on the pathogenesis of PCOS. Best Prac Res Clin Endocrinol Metabol. 2018;32(3):271-81. https://doi.org/ 10.1016/ j.beem.2018.03.008

5. Hartmann G, McEwen B. Insulin resistance and Polycystic ovary syndrome (PCOS): Part 2. Diet and Nutritional Medicine. J Australian Trad Med Soc. 2019;25(1):18.

6. Yilmaz B, Vellanki P, Ata B, Yildiz BO. Metabolic syndrome, hypertension, and hyperlipidemia in mothers, fathers, sisters, and brothers of women with polycystic ovary syndrome: a systematic review and meta-analysis. Fertil Steril. 2018;109(2):356-64.e32.

https://doi.org/ 10.1016/j.fertnstert.2017.10.018

7. Khan Z, Khan R, Bukhari AS, Ahmad W. Comparative effectiveness of ovulation induction therapy in women with polycystic ovarian syndrome. J Soc Obstet Gynaecol Pak. 2017;7(3):128-32.

8. Tanbo T, Mellembakken J, Bjercke S, Ring E, Åbyholm T, Fedorcsak P. Ovulation induction in polycystic ovary syndrome. Acta Obstet Gynecol Scand. 2018;97(10):1162-7. https://doi.org/ 10.1111/aogs.13395

9. Legro RS. Ovulation induction in polycystic ovary syndrome: current options. Best Prac Res Clin Obstet Gynaecol. 2016;37:152-9. https://doi.org/10.1016/j.bpobgyn.2016.08.001

10. Evans A, Hoeger KM. PCOS in adolescence: Towards a better diagnosis and treatment. Curr Opinion Endoc Metabol Res. 2020;12;105-11. https://doi.org/10.1016/j.coemr.2020.04.010

11. Kooti W, Ahangarpoor A, Ghasemiboroon M, Sadeghnezhadi S, Abbasi Z, Shanaki Z, et al. Effect of Apium graveolens lea extract on serum level of thyroid hormones in male rat. J Babol Univ Med Sci. 2014;16(11):44-50

12. Heidari-Soreshjani S, Asadi-Samani M, Yang Q, SaeediBoroujeni A. Phytotherapy of nephrotoxicity-induced by cancer drugs: An updated review. J Nephropathol 2017;6(3):254-63. https://doi.org/10.15171/jnp.2017.41

13. Parsaei P, Bahmani M, Naghdi N, Asadi-Samani M, RafieianKopaei M. A review of therapeutic and pharmacological effects of thymol. Der Pharm Lett. 2016;8(2):150-4

14. Vlaisavljevic S, Kaurinovic B, Popovic M, Djurendic-Brenese $\mathrm{M}$, Vasiljevic B, Cvetkovic D, et al. Trifolium pratense L. as a potential natural antioxidant. Molecules. 2014;19(1):713-25. https://doi.org/ 10.3390/molecules19010713

15. Zhang H, Zhao J, Shang H, Guo Y, Chen S. Extraction, purification, hypoglycemic and antioxidant activities of red clover (Trifolium pratense L.) polysaccharides. Int J Biol Macromol. https://doi.org/10.1016/j.ijbiomac.2020.01.194 2020;148:750-60.

16. Khazaei M, Pazhouhi M, Khazaei S. Evaluation of hydroalcoholic extract of Trifolium Pratense L. for its anti-cancer potential on U87MG Cell line. Cell J. 2018;20(3):412 https://doi.org/10.22074/cellj.2018.5380

17. Krenn L, Unterrieder I, Ruprechter R. Quantification of isoflavones in red clover by high-performance liquid chromatography. J Chromatogr B. 2002;777(1-2):123-8 https://doi.org/10.1016/s1570-0232(02)00079-x.

18. Kanadys W, Baranska A, Jedrych M, Religioni U, Janiszewska M. Effects of red clover (Trifolium pratense) isoflavones on the lipid profile of perimenopausal and postmenopausal womenA systematic review and meta-analysis. Maturitas. 2020;132:7 16. https://doi.org/10.1016/j.maturitas.2019.11.001

19. Fritz H, Seely D, Flower G, Skidmore B, Fernandes R, Vadeboncoeur S, et al. Soy, red clover, and isoflavones and breast cancer: a systematic review. Plos One. 2013;8(11):e81968

https://doi.org/10.1371/journal.pone.0081968

20. Rezvanfar M, Ahmadi A, Shojaei-Saadi H, Baeeri M, Abdollahi M. Molecular mechanisms of a novel selenium-based complementary medicine which confers protection against hyperandrogenism-induced polycystic ovary. Theriogenology. 2012;78(3):620-31.

https://doi.org/10.1016/j.theriogenology.2012.03.008

21. Osuka S, Nakanishi N, Murase T, Nakamura T, Goto M, Iwase A et al. Animal models of polycystic ovary syndrome: A review of hormone induced rodent models focused on hypothalamus pituitary ovary axis and neuropeptides. Reprod Med Biol. 2019;18(2):151-60. https://doi.org/10.1002/rmb2.12262

22. Reddy PS, Begum N, Mutha S, Bakshi V. Beneficial effect of curcumin in letrozole induced polycystic ovary syndrome. Asian Pac J Reprod. 2016;5(2):116-22. https://doi.org/ 10.1016/j.apjr.2016.01.006

23. Kakkar P, Das B, Viswanathan PN. A modified spectrophotometric assay of superoxide dismutase. Indian J Biochem Biophys. 1984;21(2):130-2 
24. Beers RF, Sizer IW. A spectrophotometric method for measuring the breakdown of hydrogen peroxide by catalase. J Biol Chem. 1952;195(1):133-40

25. Jollow DJ, Mitchell JR, Zampaglione N, Gillette JR. Bromobenzene-induced liver necrosis. Protective role of glutathione and evidence for 3,4-bromobenzene oxide as the hepatotoxic metabolite. Pharmacology. 1974;11(3):151-69

26. Ohkawa H, Ohishi N, Yagi K. Assay for lipid peroxides in animal tissues by thiobarbituric acid reaction. Analytical biochemistry. 1979;95(2):351-8

27. Green LC, Wagner DA, Glogowski J, Skipper PL, Wishnok JS, Tannenbaum SR. Analysis of nitrate, nitrite, and [15N] nitrate in biological fluids. Anal Biochem. 1982;126(1):131-8

28. Karbalay-Doust S, Noorafshan A. Stereological estimation of ovarian oocyte volume, surface area and number: application on mice treated with nandrolone decanoate. Folia Histochem Cytobiol.

2012;50:275-279.

https://doi.org/ 10.5603/fhc.2012.0037

29. Caldwell ASL. Unravelling the role of androgens in polycystic ovary syndrome. PhD [dissertation]. ANZAC Research Institute: The University of Sydney; 2018. Available from http://hdl.handle.net/2123/18129

30. Huang J, Ding Y, Li Z. The regulation of the follicular synchronization and sensitivity of rats with PCOS by AMH during prolonged pituitary downregulation. Gene. 2019;721:144106. https://doi.org/10.1016/j.gene.2019.144106

31. Shabbir S, Naz L, Khan Z, Memon AA. Beneficial effects of Prunus dulcis (almond oil) on letrozole-induced polycystic ovarian syndrome in rats. Int J Pure App Biosci. 2019;7(3):1-14. https://doi.org/10.1016/j.jtumed.2020.02.002

32. Weber K, Setchell K, Stocco D, Lephart E. Dietary soyphytoestrogens decrease testosterone levels and prostate weight without altering LH, prostate 5alpha-reductase or testicular steroidogenic acute regulatory peptide levels in adult male Sprague-Dawley rats. J Endocrinol. 2001;170(3):591-9. https://doi.org/10.1677/joe.0.1700591

33. Zilaee M, Mansoori A, Ahmad HS, Mohaghegh SM, Asadi M, Hormoznejad R. The effects of soy isoflavones on total testosterone and follicle-stimulating hormone levels in women with polycystic ovary syndrome: a systematic review and meta-analysis. Eur J Contracept Reprod Health Care. 2020:1-6. https://doi.org/10.1080/13625187.2020.1761956

34. Zhang T, Chi X. Estrogenic properties of genistein acting on FSHR and LHR in rats with PCOS. Pol J Vet Sci. 2019;22(1):8390. https://doi.org/ 10.24425/pjvs.2019.127075

35. Rajaei S, Alihemmati A, Abedelahi A. Antioxidant effect of genistein on ovarian tissue morphology, oxidant and antioxidant activity in rats with induced polycystic ovary syndrome. Int J Reprod BioMed. 2019;17(1):11-22. https://dx.doi.org/10.18502\%2Fijrm.v17i1.3816

36. Beck V, Rohr U, Jungbauer A. Phytoestrogens derived from red clover: an alternative to estrogen replacement therapy? Steroid Biochem Mol Biol. 2005;94(5):499-518. https://doi.org/10.1016/j.jsbmb.2004.12.038

37. Bannigida DM, Nayak SB. Coronary risk factors and oxidative stress in women with PCOS. Indian J Med Biochem. 2019;23(2):268. https://doi.org/ 10.5005/jp-journals-10054-0101

38. Santoso B, Zuhri AS, Alkaff FF. Hyperbaric oxygen therapy effect on androgen receptor and superoxide dismutase in insulin-resistant polycystic ovary syndrome. J Int Dental Med Res. 2020;13(1):144-8

39. Mostafa M, Ferdousi S, Sultana S, Akhter A. Autonomic impairment and oxidative stress: Relationship in PCOS patients. J Bangladesh Soc Physiol. 2019;14(2):82-8

40. Plenchette S, Paul C, Bettaieb A. Nitric oxide and platinumderivative-based regimens for cancer treatment: from preclinical studies to clinical trials. Nitric Oxide (Donor/Induced) in Chemosensitizing: Elsevier; 2017. p. 91-103

41. Kashfi K, Duvalsaint PL. Nitric oxide donors and therapeutic applications in cancer. Nitric Oxide Donors: Elsevier; 2017. p. 75-119

42. Savić-Radojević A, Mažibrada I, Djukić T, Stanković ZB, PlješaErcegovac M, Sedlecky K, et al. Glutathione S-transferase (GST) polymorphism could be an early marker in the development of polycystic ovary syndrome (PCOS) - an insight from non-obese and non-insulin resistant adolescents. Endokrynol Pol. 2018;69(4):366-74. https://doi.org/ 10.5603/EP.a2018.0034

43. Sulaiman MA, Al-Farsi YM, Al-Khaduri MM, Saleh J, Waly MI. Polycystic ovarian syndrome is linked to increased oxidative stress in Omani women. Int J Women Health. 2018;10:763. https://doi.org/ 10.2147/IJWH.S166461

44. Deligeoroglou E, Vrachnis N, Athanasopoulos N, Iliodromiti Z, Sifakis S, Iliodromiti S, et al. Mediators of chronic inflammation in polycystic ovarian syndrome. Gynecol Endocrinol. https://doi.org/10.3109/09513590.2012.683082

45. Fatima Q, Amin S, Kawa IA, Jeelani H, Manzoor S, Rizvi SM, et al. Evaluation of antioxidant defense markers in relation to hormonal and insulin parameters in women with polycystic ovary syndrome (PCOS): A case-control study. Diabet Metab Syndr. 2019;13(3):1957-61. https://doi.org/ 10.1016/j.dsx.2019.04.032 